\title{
Supplier-Customer Geographic Distance and Audit Fee
}

\author{
Mingming Zhang \\ School of Management, Jinan University, Guangzhou, China \\ Email: zmm19951211@163.com
}

How to cite this paper: Zhang, M. M. (2020). Supplier-Customer Geographic Distance and Audit Fee. Modern Economy, 11, 581-599.

https://doi.org/10.4236/me.2020.112043

Received: January 16, 2020

Accepted: February 24, 2020

Published: February 27, 2020

Copyright $\odot 2020$ by author(s) and Scientific Research Publishing Inc. This work is licensed under the Creative Commons Attribution International License (CC BY 4.0).

http://creativecommons.org/licenses/by/4.0/

\begin{abstract}
Audit fees have always been a topic of concern in the field of accounting research at home and abroad. As far as the existing literature is concerned, the research on audit fees is mostly concentrated on the characteristics of the firm and the characteristics of the audited entities. In recent years, as the supply chain has become the focus of attention, customer characteristics have gradually been taken into account in the scope of factors affecting audit fees. This paper selects the geographical distance between the customer and the company as a customer feature for research, and introduces geographical location factors into the field of audit fees, and explores what impact the distance between customers and the company would have on the audit fees. Earlier studies indicated that the two key factors affecting audit fees are auditor efforts and litigation risks. This paper uses the data of the top five customers disclosed by the Shanghai-Shenzhen A-share listed companies in 2009-2016 to analyze the information asymmetry of long-distance customer affects these two key factors to explore the impact on audit costs. The study found that: 1) The farther the listed company is from the main customers, the higher the audit fee is, and vice versa. 2) The impact of listed company customer distance on audit fees is different between groups in different levels of customer concentration and different levels of analyst attention. This paper provides evidence that different customer geographic characteristics have different impacts on audit fees.
\end{abstract}

\section{Keywords}

Geographic Distance, Information Asymmetry, Audit Fee, Geographical

\section{Introduction}

Auditing fee refers to the remuneration paid by the audited unit for the professional auditing services provided by the accounting firm, and is the value per- 
formance of the supply and demand relationship of audit services between the accounting firm and the audited unit. The audit fees paid by the audited unit to the accounting firm can fairly reflect the value of professional services provided by the accounting firm. Excessively high or low audit fees will affect the quality of the audit work and the independence of the certified public accountant, thus affecting the vital interests of many stakeholders. Therefore, due to its importance and practical value, scholars have been paying close attention to the issue of audit fee pricing. Among these thousands of related literatures, Simunic's research on audit costs is particularly classical. Based on this paper, many valuable research literatures emerged at the historic moment. It is generally believed that audit pricing mainly depends on the auditor's the level of effort, the client's audit risk, and the relative bargaining power of the auditor and the client. The research content of these documents mostly studies the influencing factors of audit fees from the aspects of earnings management, customer scale, equity structure, internal control, etc., but relatively few studies on the influence of geographical factors on audit fees.

Since the introduction of geographic location characteristics into the field of finance and accounting research, a large number of studies have emerged about its influence on the decision-making of economic subjects and their consequences. As one of the important geographic location characteristics, geographic distance has attracted a lot of scholars' attention. Although today's era is a fast-developing Internet era, geographical differences will still cause obstacles to information exchange. The increase in distance means the emergence of various costs, which will significantly affect the ability of both parties to obtain information and the degree of asymmetry this intensifies. At present, related research mainly focuses on corporate behavior, investor behavior, bank credit, securities analysts, auditors, etc., that is, investors, analysts, and auditors have geographical advantages or geographical preferences. In recent years, some scholars have found that geographical location is also an important factor that affects audit quality and audit fees. However, most of them focus on the study of the geographical location between accounting firms and audited companies. They believe that the distance between audit firms will affect the geography of accounting firms. Advantages and the ability to obtain information have an impact on audit costs, but rarely involve the impact of geographic location between the audited company and other stakeholders on audit costs.

To sum up, according to the research results of previous scholars, the increase of geographic distance will aggravate information asymmetry, and the information asymmetry between customers and suppliers is mainly reflected in the information advantages of suppliers, and customers as information disadvantages, it is difficult Obtaining private information depends more on public information. Will the supplier take advantage of this information to engage in speculation or whitewash financial statements and release a good signal to customers to obtain high expectations from customers? When this information advantage increases with geographical distance, the contraction and reduction of customer 
information have even led to customers becoming the dominant party of information. Knowing more about the private information of suppliers can form a good cooperation and synergy efficiency, and can correctly evaluate the performance of the company. Whether this information advantage will supervise and constrain the opportunistic behavior of management and give play to the effectiveness of customer supervision? Customers significantly influence the company's innovation activities, inventory management, and earnings management, which have a significant impact on the company, and then affect audit costs. To this end, this article will start from the geographical distance between the audited company and its top five customers, and study its impact on audit costs, as well as the reconciliation of this impact under different customer concentration, whether the two roles are combined, and different analysts' tracking situations effect.

\section{Literature Review and Research Hypothesis}

\subsection{Research on Supplier-Customer Geographic Distance}

Geographical distance refers to the spatial distance between two economic agents, also known as geographical proximity. Geographical distance is often used to measure the cost of obtaining information. Even with the development of modern information dissemination technology, geographical distance still hinders the transmission of information between market participants, especially the transmission of some "soft information" (Stein, 2002). According to transaction cost theory, if the geographic distance between market participants is short, the degree of information asymmetry is reduced and transaction costs are reduced. The increase of geographical distance will lead to the need to spend more time, energy, money and other resources to collect relevant information of listed companies, weaken the information acquisition ability of economic entities, and increase the degree of information asymmetry. Therefore, different geographical distances also mean different degrees of information asymmetry. For information asymmetry between different economic subjects, the impact is also different. A lot of relevant literature has been studied at home and abroad.

For analysts, geographic distance determines how easy it is for security analysts to obtain private information and the cost of information acquisition (Wang, Wang, \& Lu, 2016). In the dual sense of economics and statistics, compared with non-local analysts, the advantages of local analysts in the sample group of companies with less information disclosure and higher earnings smoothness are more significant. It's derived from the study that the financial forecast made by the forecaster is related to its distance from the financial center, and the short-term forecast of stock returns by the closer analysts often causes higher market response (Malloy, 2005). Li Dongxin et al. researched 6854 analyst reports included in the Wind database from 2005 to 2007 and found that in the analyst market in China, various phenomena indicate that local advantages are significant, which is unique to China. The economic environment is inseparable 
in the context of the institutional environment, and this phenomenon is even more pronounced in state-owned samples (Li, Li, \& Zhang, 2011).

Geographical distance also has an impact on audit quality. In 2012, Choi et al. conducted in-depth research to prove that the concept of geographical proximity can promote local accounting firms to form more effective supervision of clients, and enable accounting firms to grasp the overall operating status of clients and Future development and other information, so that the audit quality can be effectively improved. However, there is also an opposing view that when auditing local clients, local auditors have lower audit quality than non-local ones. For example, Wang et al. found in 2008 that compared with non-local auditors, local auditors have much lower probability of non-standard opinions from customers controlled by local governments. Pei and Du empirically researched the auditor-company geographical proximity to improve the audit quality based on the data of A-share listed companies from 2001 to 2011 (Pei \& Du, 2015). At the same time, the supervision intensity weakened the auditor-company geographical proximity and audit Positive correlation between quality. Shen et al. studied the collusion effect of local auditors from the perspective of audit fees and audit quality, and the results show that local auditors and companies with high levels of information asymmetry have earnings management behaviors. Collusion, and further pointed out that earnings management companies with a high degree of information asymmetry are more likely to choose local auditors for auditing (Shen, Wang, \& Wu, 2017). Liu Wenjun used listed companies from 2008 to 2011 as research samples and used more rigorous data processing, which finally proved that the auditor-client distance has a negative correlation with audit quality, that is, the audit quality of local auditors is high to non-local auditors (Liu, 2014).

Regarding other stakeholders of listed companies, Zhang Honghui et al. research shows that the farther the independent director is from the listed company, the lower the quality of the company's financial report; The further the independent director is from the listed company, the number of independent directors attending is less, which in turn affects the quality of the company's financial reports, which is direct evidence that geographical distance affects the performance of independent directors and exerts a supervisory role (Zhang, Ping, \& Zhang, 2019). Cheng et al. reflected the information and transaction status between major customers and suppliers through geographical distance. It was found that the closer the geographical distance, the more helpful it is to strengthen the negotiation advantage of major customers and promote the provision of supplier companies' more robust accounting information (Cheng, Wan, \& Li, 2019). Starting from the governance effect hypothesis of the geographic proximity of large customers, empirical research shows that the closer the geographical distance between the large customer and the company, the smaller the company's tendency to violate the rules and the lower its severity, that is, the geographic proximity of major customers has inhibited company violations (Wan, Cheng, \& Yang, 2019). Li Bin research found that it is difficult 
for the parent company to obtain sufficient information about its subsidiaries, and it becomes increasingly difficult to control and control its subsidiaries, and management may produce opportunistic behaviors, leading to a decline in the quality of the company's financial information (Li, 2015).

To sum up, geographical distance works from two aspects: First, geographic distance affects the degree of information asymmetry. The information passed between different economic entities is not only public accounting information or hard information such as evaluation reports. It is also worth paying attention to the company's private information, unpublished and informal information. This soft information needs to be relevant only through frequent contact with management and key employees, can they obtain it through personal relationships or on-site visits. Geographical distance greatly reduces the chance of face-to-face communication, and it is not easy for the two parties to form a close cooperative relationship, which makes the acquisition of soft information a natural disadvantage. In addition, different geographical locations will cause cultural isolation and institutional differences, and there will be loss and distortion of long-distance information transmission, increasing the risk of misreading and distortion, reducing the efficiency of information transmission, and then aggravating the degree of information asymmetry.

Second, geographic distance reduces the effectiveness of supervision. Monitoring means consuming resources, and paying attention to costs becomes a determining factor for stakeholders to implement monitoring. Monitoring costs generally include the cost of collecting and sorting various types of information, as well as the cost of various contract amendments and renegotiations in the face of the company's potential moral hazard. Geographical distance brings huge expenses in terms of transportation. At the same time, long-distance transportation time will reduce the willingness of supervisors to go out and work energy. Geographical distance will also weaken the company's own degree of self-discipline, it is easier to make irregularities such as whitewashing performance and operating earnings, increasing the cost of risk.

\subsection{Hypothesis Development}

Audit costs are mainly composed of three parts: first, the cost of audit products, that is, the costs required by the firm to perform necessary audit procedures and issue audit reports from the start of the audit project to the submission of the audit report; the second is the risk cost, That is, the expected loss costs caused by the existence of audit risks; the third is the normal profit of accounting firms. Among them, the cost of audit products generally depends on characteristics such as scale, corporate accounting robustness and corporate governance level; audit risks include major misstatement risks and inspection risks of financial statements. In the study of Simunic, he compared the company's operating risks with Financial risk is used as a measure of audit risk. As a stakeholder, the relationship between the customer and the supplier will inevitably affect the business risk and financial risk of the enterprise, and then affect the audit risk and 
audit fees.

Specifically, on the one hand, when geographic distances narrow the relationship between suppliers and customers, and reduce the degree of information asymmetry between suppliers and customers, Song Yu believes that the convenience of geographical locations can be used with company managers or employees. Interactive conversations and the establishment of personal relationships will bring more significant advantages in private information, and the company and customers will form longer and more stable cooperation. In addition, geographical closeness will also reduce transaction costs for both parties, enhance the ability of suppliers to serve customers, promote both parties to increase sales and reduce costs (Kim \& Wemmerlöv, 2015), improve inventory management efficiency, and improve the profitability of both parties, which in turn reduces the company's operating risk. When the company is performing well, the possibility of financial fraud is reduced, the potential for violations is also low, and the inherent audit risk is low, which reduces audit costs.

On the other hand, when geographic distance becomes an obstacle to information transmission, and due to the consideration of transportation costs and communication costs, customers become a party with an information disadvantage, weakening the supervision of the company and failing to exert its governance role. Supplier management is motivated to use its informational superiority to report more good news to influence customer expectations of the company's prospects, and unwilling to predict bad news about business performance (Basu, 1997). And may even increase profits by attracting new customers or maintaining existing customer relationships, and auditors increase investment in audit activities, substantive testing and analysis procedures, etc., thereby increasing audit fees. When a client discovers an enterprise's opportunistic behavior, it is very likely that it will cause a transaction interruption, cause the enterprise to fall into a larger operating risk and even cause a financial crisis, and then affect the audit risk and increase the audit costs.

Therefore, based on the theory of information asymmetry, this article proposes the first hypothesis:

H1: The geographic distance between customers and suppliers increases, and audit costs increase.

\subsection{Customer Concentration, Geographic Distance and Audit Fee}

Market competition is becoming increasingly fierce, and collaboration between suppliers and companies is essential. Customers are often larger than companies, have stronger bargaining power, and high customer concentration can affect the company's production operations and financial decisions. Increased customer concentration indicates that customers have a higher status and have a greater right to speak. As a party relying on large customers, the company has a relatively weak right to speak, and customers have greater bargaining power, which may require the company to lower prices and extend business. Credit or higher 
inventory levels, reducing the company's profit margin, and the company making concessions will affect the company's account receivable turnover rate and weaken the company's ability to expand production, which is not conducive to the company's continued operation and development; Increased customer concentration will allow the company to make a large number of specialized investments in order to strengthen the cooperative relationship, resulting in a large number of fixed costs, and large customers may interrupt the transaction at any time or establish alliances with competitors in the same industry. Once the transaction with the customer Termination, this special investment will be greatly devalued, and the company will face production interruption, a significant decline in revenue and other conditions, the company may fall into a financial crisis. Therefore, increasing customer concentration may increase the motivation of the company's management to engage in opportunistic behavior. In order to maintain important customer relationships, the management needs to send a signal of good company operation. When the performance is not satisfactory, it is more inclined to whitewash Performance or earnings management or selective disclosure to avoid bad news.

When a long-distance brings the company's information advantages, it provides favorable conditions for manipulating financial information, and when it faces large customers, the company has a strong incentive to whitewash its performance to meet customers. Therefore, when large customers focus on long distances, the company has a larger Risks, the credibility of the quality of the information disclosed is low, which increases audit costs and audit risks, resulting in higher audit costs.

This article therefore proposes a second hypothesis:

$\mathrm{H} 2$ : Customer concentration will strengthen the effect of customer geographic distance on audit costs.

\subsection{Number of Analysts, Geographic Distance and Audit Fee}

The analyst plays a very important role as an information transmission intermediary. On the one hand, the analyst can more easily discover the private information of the company. On the other hand, the analyst's report can help identify and disseminate the information disclosed by the company. The number of analysts tracking is usually regarded as a proxy for obtaining private information, and it is also regarded as an indicator of the enterprise information environment (Lang, Lins, \& Miller, 2003). The analyst tracking can improve the information environment of the enterprise and alleviate information Symmetrical situation. Empirical research shows that follow-up by analysts can effectively alleviate the problem of information asymmetry between listed companies and information users, reduce audit risks, and auditors can complete them efficiently according to standard audit procedures, auditing costs have also been reduced accordingly (Zhou \& Zhao, 2015). It's found that analysts' attention as an important force of corporate external governance has a substitution effect with audit supervision to 
a certain extent (Li \& Ren, 2013). Gotti et al. found that management shareholding and analyst concerns were negatively related to audit costs (Gotti, Han, \& Higgs, 2011). In summary, analysts act as information intermediaries to pass relevant information to the market and information users, reducing the degree of information asymmetry between customers and suppliers, thereby reducing audit risks and audit costs.

Therefore, this article proposes a fourth hypothesis:

H3: For companies with a higher degree of analyst attention, the impact of customer geographic distance on audit costs is weakened.

\section{Sample Data and Research Design}

\subsection{Sample Data}

The research sample of this article is the 2009-2016 data of Shanghai and Shenzhen A shares. The reason why the sample period started in 2009 is that only since 2009 have more companies voluntarily disclosed the names and sales of the top 5 customers. To this end, this article manually collected the sales of the top 5 customers of listed companies as of 2016 Amount and proportion information. All financial data and company nature data of the sample companies are from the CSMAR database. The CSMAR database is currently the largest, most accurate and comprehensive economic and financial research database in China. Based on academic research needs, Shenzhen Guotai'an Education Technology Co., Ltd. draws on the professional standards of the internationally renowned databases such as CRSP and Compustat to establish the CSMAR database.

In the process of sample selection, this paper processed the following data: 1) excluding financial companies; 2) excluding companies with incomplete required variable data. In this paper, a total of 3650 sample observations were obtained, and winsorize processing was performed on the $1 \%$ quantile of the continuous variable.

\subsection{Variable Definition}

1) Variables for Supplier-Customer Geographical Distance

Based on previous literature references, this article collects the names and registered addresses of the top five customers disclosed by listed companies, uses Google Maps to locate the latitude and longitude coordinates of the customer and the company's location, and calculates the geographical distance between the two based on the coordinates. Considering that each company has more than one customer per year and corresponds to multiple geographical distances, this article uses the following two methods to deal with.

First, collect the sales of customers who can calculate the geographical distance disclosed by the company in the current year, convert them into the proportion of the sales of the top five customers, use this ratio as the weighted weight to calculate the customer's weighted average distance, and then take the natural logarithm to get Lndis1. 
Second, based on the total number of customers who can calculate geographic distance disclosed by the company in the current year, calculate the average customer distance according to the arithmetic average, and then take the natural logarithm to obtain Lndis2.

The larger the values of Lndis1 and Lndis2, the farther the customer is from the enterprise.

2) Selection of control variables

With reference to previous research on audit costs, this paper controls the asset-liability ratio (Lev), return on assets (Roa), company size (Size), and audit firm type (Big4) when examining the impact of client geographic distance on audit costs), Current ratio (Liudong), accounts receivable ratio (Rec), inventory ratio (Inv), company growth (Growth), industry dummy variable (Industry), annual dummy variable (Year). See Table 1 for specific variable definitions.

\subsection{Empirical Model}

In order to test the hypothesis 1 proposed in this article, that is, the relationship between the geographical distance between the supplier and the customer and the audit cost, this paper constructs a regression Equation (1):

$$
\begin{aligned}
\text { Lnfee }= & \beta_{0}+\beta_{1} \text { Lndis }+\beta_{2} \text { Big } 4+\beta_{3} \text { Rec }+\beta_{4} \text { Inv }+\beta_{5} \text { Lnsize }+\beta_{6} \text { Roa } \\
& +\beta_{7} \text { Liudong }+\beta_{8} \text { Lev }+\beta_{9} \text { Growth }+ \text { Ind }+ \text { Year }
\end{aligned}
$$

In the regression model, this paper chooses two indicators to measure the geographical distance: 1) Natural logarithm of arithmetic average distance; 2)

\begin{tabular}{|c|c|}
\hline Variables & Definitions \\
\hline Lnfee & Natural logarithm of audit costs \\
\hline Lndis 1 & $\begin{array}{l}\text { The natural logarithm of the weighted average distance between the } \\
\text { listed company and the the top five customers, weighted by sales revenue }\end{array}$ \\
\hline Lndis2 & $\begin{array}{l}\text { Natural logarithm of the arithmetic average distance } \\
\text { between a listed company and the top five customers }\end{array}$ \\
\hline Lev & Financial leverage, total liabilities/total assets \\
\hline Roa & Return on equity, profit after tax/total assets \\
\hline Lnsize & Company size, natural logarithm of company total assets \\
\hline Growth & Sales growth rate \\
\hline $\operatorname{Rec}$ & total accounts receivable/asset \\
\hline Inv & Prtotal inventory/total assets \\
\hline Big4 & the accounting firm is 1 for the Big Four, otherwise it is 0 \\
\hline Liudong & Current assets/current liabilities \\
\hline $\mathrm{CC}$ & $\begin{array}{l}\text { The sum of the sales of the top five customers of the company, and compared } \\
\text { with the median concentration of customers in the same industry } \\
\text { in the same year, if it is greater than the median, it is } 1 \text {, otherwise it is } 0\end{array}$ \\
\hline Analyst & $\begin{array}{l}\text { The number of analysts tracking is greater than } \\
\text { the median of the industry is } 1 \text {, otherwise it is } 0\end{array}$ \\
\hline
\end{tabular}

Table 1. Variable definitions. 
Natural logarithm of weighted average distance of sales ratio. Lnfee indicates the natural logarithm of the end-year audit costs of listed companies, the data comes from CSMAR.

In the hypothesis 1 , the research mainly focused on the Lndis coefficient. If the coefficient $\beta_{1}$ is significantly positive, it means that the farther the geographical distance of the listed company's customers is, the higher the company's audit costs, and the closer the geographical distance of the listed company's customers, the more the company's audit costs Low, hypothesis 1 is verified. In order to verify Hypothesis 2 and Hypothesis 3 of this article, that is, compared with the case where the concentration of customers is low, when the concentration of customers is high, the positive correlation between customer geographic distance and audit costs is more significant; when the analyst's attention is higher, the positive correlation between the customer geographical distance and the audit costs is no longer significant. In this paper, the regression Equation (1) is used to perform group regression after setting the group dummy variables, and the main concern is the difference between the groups of the Lndis coefficients under different groups.

\section{Empirical Test Results and Analysis}

\subsection{Descriptive Statistics}

Table 2 reports descriptive statistics of the variables in the entire sample. From Table 2, Lndis1 and Lndis2 are indicators that measure the geographical distance between the company and the customer. The average value of Lndis1 is 6.2749 , the minimum value is 1.4444 , the maximum value is 9.1556 , the average value of Lndis2 is 6.4076, the minimum value is 1.8389 , and the maximum value is 8.9857 . This result shows that the average geographical distance between different listed companies and the top five customers varies greatly. Lnfee is a measure of audit costs, with an average value of 13.5047, a minimum value of 12.2161, and a maximum value of 15.7826 .

In addition, the minimum value of the asset-liability ratio Lev is 0.0395 and the maximum value is 0.8866 , indicating that the level of financial leverage used by listed companies in China is very different. The average current ratio of listed companies is 2.5099 , the minimum value is 0.2635 , and the maximum value is 25.5127, indicating that the current assets and current liabilities ratios of listed companies are very different, reflecting that there are also large differences in the financial risks of different companies, which will also affect Audit risks of listed companies, which in turn affect audit costs. Whether the Big4 average of listed companies audited by the Big Four accounting firms is 0.0538 , which indicates that the proportion of Chinese listed companies audited by the Big Four accounting firms is relatively small, which also results in large differences in audit quality and audit costs of listed companies in China. The average analyst's indicator, Analyst, has an average value of 0.4274 , indicating that nearly $42.74 \%$ of the sample is highly concerned by analysts. 
Table 2. Descriptive statistics.

\begin{tabular}{ccccccc}
\hline variable & $\mathrm{N}$ & mean & $\mathrm{sd}$ & $\mathrm{min}$ & $\mathrm{p} 50$ & $\max$ \\
\hline Lnfee & 3367 & 13.5047 & 0.6694 & 12.2161 & 13.3847 & 15.7826 \\
Lndis1 & 3367 & 6.2749 & 1.4887 & 1.4444 & 6.5212 & 9.1556 \\
Lndis2 & 3367 & 6.4076 & 1.3618 & 1.8389 & 6.6117 & 8.9857 \\
Liudong & 3367 & 2.5099 & 3.4191 & 0.2635 & 1.4672 & 25.5127 \\
Growth & 3367 & 0.2368 & 0.5759 & -0.6125 & 0.1395 & 4.7000 \\
Lev & 3367 & 0.4476 & 0.2111 & 0.0395 & 0.4556 & 0.8866 \\
Roa & 3367 & 0.0450 & 0.0481 & -0.1198 & 0.0398 & 0.1993 \\
Lnsize & 3367 & 22.0215 & 1.1922 & 19.7290 & 21.8864 & 25.2876 \\
Inv & 3367 & 0.1401 & 0.1252 & 0.0000 & 0.1100 & 0.6200 \\
Rec & 3367 & 0.1059 & 0.0981 & 0.0003 & 0.0778 & 0.4417 \\
Big4 & 3367 & 0.0538 & 0.2256 & 0 & 0 & 1 \\
Analyst & 3367 & 0.4274 & 0.4948 & 0 & 0 & 1 \\
\hline
\end{tabular}

\subsection{Empirical Results}

Table 3 tests hypothesis 1 by multiple regression. The results show that the regression coefficient of the geographic distance and audit costs of listed companies and customers is significantly positive. The coefficient of lndis1 is 0.0145 , which is significant at the level of $p<0.01$. The coefficient of lndis2 is 0.0125 , which is significant at the level of $p<0.05$, which is in line with expectations.

When the listed company is farther away from the top five customers, the higher the degree of information asymmetry between the two, the customer is lacking in contact with the listed company and can only obtain relevant information from public information. On the one hand, the company faces customers who do not know the truth, and due to the need to maintain major customers and to send good signals to the outside world, opportunistic behavior may occur, not reporting bad news, only reporting good news, and even whitewashing performance or performing earnings management. However, it is difficult for customers to find possible false statements in the company's information disclosure, the effectiveness of supervision of the company is weakened, and its governance role cannot be exerted. As a result, the quality of information is reduced, auditors reduce their reliance on corporate financial reports, and increase audit activity Investment, substantive testing and analysis procedures, etc., increase audit costs and audit fees. On the other hand, the long-distance brings the increase of transportation cost and communication cost, and it will also cause distortion and inefficiency in the information transmission process. The cooperation relationship between suppliers and customers often requires a lot of communication and consultation. It shows that there are a large number of relationship-based transactions between suppliers and customers. The obstacle of geographical distance will reduce the willingness of both parties to communicate 
Table 3. Supplier-customer geographic distance and audit cost.

\begin{tabular}{|c|c|c|}
\hline & (1) & (2) \\
\hline & Lnfee & Lnfee \\
\hline \multirow[t]{2}{*}{ Lndis1 } & $0.0136^{\star * *}$ & \\
\hline & $(2.60)$ & \\
\hline \multirow[t]{2}{*}{ Lndis2 } & & $0.0110^{*}$ \\
\hline & & $(1.91)$ \\
\hline \multirow[t]{2}{*}{$\operatorname{Rec}$} & 0.0964 & 0.1010 \\
\hline & $(1.27)$ & $(1.32)$ \\
\hline \multirow[t]{2}{*}{ Inv } & $0.2090^{* * *}$ & $0.2130^{* * *}$ \\
\hline & $(2.82)$ & $(2.87)$ \\
\hline \multirow[t]{2}{*}{ Lnsize } & $0.3700^{\star * *}$ & $0.3690^{* * *}$ \\
\hline & $(39.54)$ & $(39.46)$ \\
\hline \multirow[t]{2}{*}{ Roa } & 0.1950 & 0.1950 \\
\hline & $(1.12)$ & $(1.12)$ \\
\hline \multirow[t]{2}{*}{ Lev } & $-0.1550^{* * *}$ & $-0.1530^{\star * *}$ \\
\hline & $(-2.67)$ & $(-2.64)$ \\
\hline \multirow[t]{2}{*}{ Growth } & -0.0017 & -0.0014 \\
\hline & $(-0.12)$ & $(-0.10)$ \\
\hline \multirow[t]{2}{*}{ Liudong } & $-0.0138^{* * *}$ & $-0.0136^{\star * *}$ \\
\hline & $(-5.81)$ & $(-5.75)$ \\
\hline \multirow[t]{2}{*}{ Big4 } & $0.6900^{* * *}$ & $0.6880^{\star * *}$ \\
\hline & $(14.90)$ & $(14.87)$ \\
\hline Ind & Yes & Yes \\
\hline Year & Yes & Yes \\
\hline \multirow[t]{2}{*}{ _cons } & $5.2130^{* * *}$ & $5.2290^{\star * *}$ \\
\hline & $(27.01)$ & $(26.96)$ \\
\hline$N$ & 3367 & 3367 \\
\hline
\end{tabular}

$t$ statistics in parentheses. ${ }^{*} p<0.1,{ }^{* *} p<0.05,{ }^{* *} p<0.01$.

and cooperate, affect the company's operating risks, and then affect audit risks and audit costs.

At the same time, considering that soft information contains more real information about the company, this information cannot be obtained from the channels published online. Instead, stakeholders need to use personal relationships or conduct frequent contacts with management and key employees. It can only be obtained by on-site visits. Long-distance can explain to some extent the lack of understanding between the company and customers. This will reduce the trust between the two parties and is not conducive to achieving long-term and stable cooperative relations. In addition, long-distance logistics transportation Cost is 
also a factor that affects cooperation. In the face of geographical preferences, customers are more inclined to change suppliers, requiring them to provide more business credit. Conversion costs and loss of special investment will increase the operating risks of listed companies, and auditors. The audit risk has also increased, correspondingly charging more risk premiums and increasing audit fees.

In order to explore the role of the concentration of customers on the positive correlation between geographic distance and the audit costs of listed companies, this paper performs a group test on the regression model. The regression results are shown in Table 4.

Table 4. Customer concentration, geographic distance and audit fee.

\begin{tabular}{|c|c|c|c|c|}
\hline & (1) & (2) & (3) & (4) \\
\hline & $\mathrm{CC}=0$ & $\mathrm{CC}=1$ & $\mathrm{CC}=0$ & $\mathrm{CC}=1$ \\
\hline \multirow[t]{2}{*}{ lndis1 } & 0.0038 & $0.0206^{\star * *}$ & & \\
\hline & $(0.49)$ & $(2.93)$ & & \\
\hline \multirow[t]{2}{*}{ lndis2 } & & & 0.0074 & $0.0188^{* *}$ \\
\hline & & & $(0.89)$ & $(2.41)$ \\
\hline \multirow[t]{2}{*}{ rec } & 0.1220 & 0.1570 & 0.1160 & 0.1600 \\
\hline & $(1.00)$ & $(1.43)$ & $(0.95)$ & $(1.46)$ \\
\hline \multirow[t]{2}{*}{ inv } & $0.4290^{* * *}$ & -0.0237 & $0.4290^{* * *}$ & -0.01600 \\
\hline & $(3.88)$ & $(-0.24)$ & $(3.88)$ & $(-0.16)$ \\
\hline \multirow[t]{2}{*}{ lnsize } & $0.4220^{* * *}$ & $0.3320^{* * *}$ & $0.4220^{* * *}$ & $0.3320^{\star * *}$ \\
\hline & $(34.35)$ & $(28.27)$ & $(34.35)$ & (28.18) \\
\hline \multirow[t]{2}{*}{ roa } & 0.1570 & 0.1340 & 0.1610 & 0.1410 \\
\hline & $(0.61)$ & $(0.56)$ & $(0.63)$ & $(0.59)$ \\
\hline \multirow[t]{2}{*}{ lev } & $-0.4510^{\star * *}$ & 0.0463 & $-0.4510^{\star * *}$ & 0.0495 \\
\hline & $(-5.21)$ & $(0.63)$ & $(-5.21)$ & $(0.67)$ \\
\hline \multirow[t]{2}{*}{ growth } & 0.0323 & -0.0245 & 0.0322 & -0.0244 \\
\hline & $(1.55)$ & $(-1.51)$ & (1.55) & $(-1.50)$ \\
\hline \multirow[t]{2}{*}{ liudong } & $-0.0185^{\star \star \star}$ & $-0.0103^{\star * \star}$ & $-0.0186^{\star * *}$ & $-0.0101^{\star \star \star}$ \\
\hline & $(-4.11)$ & $(-3.09)$ & $(-4.12)$ & $(-3.01)$ \\
\hline \multirow[t]{2}{*}{ big4 } & $0.6490^{* * *}$ & $0.7300^{* * *}$ & $0.6480^{* * *}$ & $0.7270^{\star * \star}$ \\
\hline & (13.79) & $(15.36)$ & (13.78) & $(15.28)$ \\
\hline Ind & Yes & Yes & Yes & Yes \\
\hline Year & Yes & Yes & Yes & Yes \\
\hline \multirow[t]{2}{*}{ _cons } & $4.3620^{* * *}$ & $5.8120^{* * *}$ & $4.3390^{\star * *}$ & $5.8220^{\star * *}$ \\
\hline & (15.34) & $(22.23)$ & $(15.22)$ & $(22.22)$ \\
\hline$N$ & 1654 & 1713 & 1654 & 1713 \\
\hline
\end{tabular}

$t$ statistics in parentheses. ${ }^{*} p<0.1,{ }^{* *} p<0.05,{ }^{* * *} p<0.01$. 
Table 4 tests hypothesis 2 by multiple regression. The results show that in the sample of companies with high customer concentration, the coefficient of lndis1 is 0.0206 , which is significant at the level of $p<0.01$, and the coefficient of lndis2 is 0.0188 , which is significant at the level of $p<0.05$, in the sample of low customer concentration The coefficient of lndis 1 is 0.0038 and the coefficient of lndis2 is 0.0074 , neither of which is significant. This result shows that, in the group with low customer concentration, geographical distance has no significant effect on increasing audit costs, while in the group with high customer concentration, geographical distance has a significant positive effect on audit costs, and the regression coefficient The larger the value, it means that when the concentration of customers is high, the effect of increasing distance on audit costs will be strengthened, and the effect of decreasing distance on audit costs will be strengthened.

Large long-distance customers do not play the integration role brought by high customer concentration, but are more inclined to show the risk effect of high customer concentration. The reason is that, first, customers are at a long distance and it is difficult to master the company. Information, and a large purchase share, in order to ensure its own interests and avoid the risk of transaction failure, it will use its high degree of discourse power to require terms that are beneficial to itself and are detrimental to the company, such as requiring a longer credit period to reduce the company's Accounts receivable turnover rate, or requiring more special-purpose investment, the company will reach a compromise clause in consideration of the high concentration of the other party, increase the company's risk, and then increase audit risk, increase audit costs, or increase inventory And cash holdings to prevent potential risks, causing auditors to implement more audit procedures, pay more audit effort, and increase audit costs; second, the company has information when facing long-distance customers Advantages, because of maintaining customers, there is an incentive to whitewash performance or false statements, long-distance just provides strong conditions for it, plus Accountants are very important to the company, and they have increased this motivation and increased the risk of major misstatement of financial reports. Taking this into account, auditors will reduce the level of trust in financial information, expand the scope of audits, and implement more audits. Procedures to increase audit costs.

As for the close-up big customers, first of all, the close-up has provided customers with a good environment for obtaining information. Customers have many channels to obtain information, such as local regulatory authorities, other stakeholders, etc., and it is easier for customers due to geographical preferences. Form a close relationship with the company. Good relationships can help customers get more private information. High customer concentration also provides customers with convenience and assistance in obtaining information. The importance of large customers makes the company willing to cooperate with customers to collect their information. Therefore, customers can make better use of their information superiority in the supply chain, collect more information, 
and combine the integration role of high customer concentration to reduce the company's operating risk and audit risk. At the same time, the company avoids close customers. Supervisory role, loss of important large customers due to fear of exposure, will reduce the motivation to whitewash performance, provide high-quality information disclosure, reduce the auditor's audit risk, and reduce audit costs.

Table 5 tests hypothesis 3 by multiple regression. The results show that in the sample of companies with lower analyst attention, the coefficient of lndis1 is 0.0151 , which is significant at the level of $p<0.05$, the coefficient of lndis 2 is 0.0125 , which is significant at the level of $p<0.1$, and at the level of analyst

Table 5. Analyst attention, geographic distance and audit fee.

\begin{tabular}{|c|c|c|c|c|}
\hline & (1) & (2) & (3) & (4) \\
\hline & Analyst $=0$ & Analyst $=1$ & Analyst $=0$ & Analyst $=1$ \\
\hline \multirow[t]{2}{*}{ lndis1 } & $0.0151^{\star *}$ & 0.0090 & & \\
\hline & $(2.45)$ & $(0.97)$ & & \\
\hline \multirow[t]{2}{*}{$\operatorname{lndis} 2$} & & & $0.0125^{*}$ & 0.0055 \\
\hline & & & $(1.85)$ & $(0.56)$ \\
\hline \multirow[t]{2}{*}{ liudong } & $-0.0115^{\star * *}$ & $-0.0179^{* * *}$ & $-0.0114^{* * *}$ & $-0.0177^{\star * *}$ \\
\hline & $(-3.56)$ & $(-3.94)$ & $(-3.52)$ & $(-3.90)$ \\
\hline \multirow[t]{2}{*}{ growth } & 0.0057 & -0.0166 & 0.0059 & -0.0160 \\
\hline & $(0.39)$ & $(-0.68)$ & $(0.40)$ & $(-0.66)$ \\
\hline \multirow[t]{2}{*}{ lev } & -0.0073 & $-0.4880^{* * *}$ & -0.0064 & $-0.4860^{* * *}$ \\
\hline & $(-0.11)$ & $(-4.70)$ & $(-0.10)$ & $(-4.68)$ \\
\hline \multirow[t]{2}{*}{ roa } & -0.0595 & 0.3790 & -0.0600 & 0.3780 \\
\hline & $(-0.26)$ & $(1.26)$ & $(-0.26)$ & $(1.25)$ \\
\hline \multirow[t]{2}{*}{ lnsize } & $0.3250^{\star \star \star}$ & $0.4370^{\star \star \star}$ & $0.3240^{\star * *}$ & $0.4370^{\star * *}$ \\
\hline & $(29.63)$ & $(29.74)$ & (29.58) & (29.68) \\
\hline \multirow[t]{2}{*}{ inv } & 0.0342 & $0.4840^{* * *}$ & 0.0377 & $0.4880^{* * *}$ \\
\hline & $(0.39)$ & $(3.77)$ & $(0.42)$ & $(3.80)$ \\
\hline \multirow[t]{2}{*}{ rec } & 0.0724 & 0.1740 & 0.0747 & 0.1810 \\
\hline & $(0.72)$ & $(1.30)$ & $(0.74)$ & $(1.35)$ \\
\hline \multirow[t]{2}{*}{ big4 } & $0.8720^{\star \star \star}$ & $0.5510^{\star * *}$ & $0.8720^{\star * *}$ & $0.5500^{\star * *}$ \\
\hline & $(16.88)$ & $(12.07)$ & $(16.86)$ & (12.05) \\
\hline Ind & control & control & control & control \\
\hline Year & control & control & control & control \\
\hline \multirow[t]{2}{*}{ _cons } & $6.1710^{\star * *}$ & $3.7090^{* * *}$ & $6.1920^{* * *}$ & $3.7300^{\star * *}$ \\
\hline & $(25.43)$ & $(10.32)$ & $(25.45)$ & (10.39) \\
\hline$N$ & 1928 & 1439 & 1928 & 1439 \\
\hline
\end{tabular}

$t$ statistics in parentheses. ${ }^{*} p<0.1,{ }^{* *} p<0.05,{ }^{* * *} p<0.01$. 
attention In a higher company sample, the coefficient of lndis1 is 0.0090 and the coefficient of lndis2 is 0.0055 , neither of which is significant. This result shows that for companies with a small number of analysts, the geographical distance between the company and the customer has a positive effect on audit costs, but for companies with more analysts, the geographical distance between the company and the customer Audit costs did not have a significant impact, validating Hypothesis 3.

The analyst's degree of attention can be used to indicate the richness of company information, especially private information. The difference between long-distance customers and short-distance customers in obtaining relevant company information is mainly private information that has not been publicly disclosed. When the number of tracked analysts is at a high level, it means that those who use the analysis report obtain a large amount of private information. For long-distance customers, the asymmetry of information brought by distance is weakened, and long-distance customers can also obtain the equivalent of close-range customers. According to previous literature, analysts reports can help stakeholders identify and disseminate information disclosed by companies to the outside world. Therefore, long-distance customers of companies that high analysts care about need not to worry about the delay or inadequacy of information transmission. When the information asymmetry between long-distance customers and the company is weakened by analysts, the impact of information asymmetry on audit costs also weakens; when the number of tracked analysts is low, the company's information environment has not improved Long-distance customers still have difficulty in obtaining private information equivalent to the number of close-range customers due to cost considerations. The degree of information asymmetry between customers and companies caused by geographical distance has not been alleviated, and the impact on audit costs has not been affected. Weakening, the farther the customer is from the company, the higher the audit costs.

\section{Conclusion}

This paper uses the publicly disclosed customer information from 2009 to 2016 to study the impact of the characteristics of the audited unit's customers on audit costs. From the perspective of the geographical distance between the customer and the company, it explains whether the information asymmetry in the supply chain will increase Company audit costs. Through theoretical analysis and empirical research, this paper finds that the farther the customer is from the company, the higher the audit cost, and the closer the distance, the lower the audit cost. The above conclusions vary with different customer concentration levels and analysts' levels of concern.

The logic behind this conclusion is that when the customer is closer to the listed company geographically, the geographical advantage is used to reduce the degree of information asymmetry. On the one hand, taking advantage of supply chain information, obtaining more private information about suppliers, and 
understanding the company's operating conditions, will help both parties to build trust and reach stable cooperation, reduce the company's operating risk, reduce audit risks and audit costs, thereby significantly reduce audit costs. On the other hand, the closer the customer is to the company, the greater the role of supervision of the company, the company's management will reduce opportunistic behavior and provide more stable and higher quality accounting information, reduce the risk of major misstatement of financial statements, and reduce audit costs.

Further grouping found that the higher the concentration of customers in listed companies, the more significant the extent to which customers obtain information on audit costs. The disadvantage of asymmetric information suffered by long-distance customers is more obvious. Large customers who have difficulty in obtaining information will pass on their own risks to the company for their own protection. The company's operating risks and fraud risks will increase, which will increase the audit cost. Strong; the motivation of close-range customers' supervision and governance is stronger, the supply chain information advantage is more significant, and the role of reducing audit costs is stronger. In a company with a large number of analysts, the information environment has been greatly improved, and customers no longer increase the information disadvantage due to the increase in geographical distance, thereby audit costs do not increase due to distance.

The conclusion has certain reference significance for the analysis of China's audit pricing direction. However, due to the subjective ability deviation and the constraints of objective conditions, the article still has many deficiencies, which are specifically reflected in three aspects: First, the geographic distance data used in this article are all manually registered addresses on the Internet, calculated from the longitude and latitude of Google Maps. It is possible that the registered place and the place of business are not in the same place, and the address is not updated in time. Although the results are in line with expectations, the accuracy and diversity of the indicators need to be further improved, such as replacing the geographical distance with the travel time between the two places; Second, this paper refers to relevant geographic location documents, and refers to the degree of information asymmetry between customers and listed companies in terms of geographic distance, ignoring the role of human differences in information transmission. The degree of information asymmetry from Shanghai to Japan is different. Cultural isolation, language differences and other factors will also affect the degree of information asymmetry. It is not enough to measure the degree of information asymmetry based on geographic distance. Third, this article studies the impact of geographic distance on audit costs. Essentially, this is the impact of supply chain relationships and customer characteristics on audit costs. The current literature on supply chain relationships focuses on customer concentration and proprietary investments. In the future, it can also be studied from the characteristics of customer stability and whether it shares the same auditor with suppliers. 
As for the practical significance of this article, China has been tracking the exploration of improvement of auditing methods by foreign professional circles, and participating in the revision and drafting of risk standards by the International Auditing and Assurance Council. Auditing costs are used as a measure of the value of auditing services. Reflecting the independence of auditing, understanding the factors affecting auditing costs will help reduce auditing risks and improve auditing quality. It will not only ensure the efficient operation of the enterprise, but also help external stakeholders to make scientific decisions. Research on geographic distance, different levels of customer concentration, and the number of analysts tracking can help understand the pricing mechanism of audit services in different backgrounds, help judge audit independence, improve the quality of public information, and be more effective in formulating The internal and external supervision method provides theoretical basis, which has benefits for the development of the enterprise and increasing the degree of marketization.

\section{Conflicts of Interest}

The author declares no conflicts of interest regarding the publication of this paper.

\section{References}

Basu, S. (1997). The Conservatism Principle and the Asymmetric Timeliness of Earnings. Journal of Accounting and Economics, 24, 215-241. https://doi.org/10.1016/S0165-4101(97)00014-1

Cheng, X. K., Wan, Q., \& Li, H. Y. (2019). Research on the Influence of Geographical Proximity of Large Customers on the Suppliers' Accounting Conservatism. Audit \& Economy Research, No. 5, 65-74.

Gotti, G., Han, S., Higgs, J. L., \& Kang, T. (2011). Managerial Ownership, Corporate Monitoring and Audit Fee. Rochester, NY: Social Science Electronic Publishing. https://doi.org/10.2139/ssrn.1406648

Kim, Y. H., \& Wemmerlöv, U. (2015). Does a Supplier's Operational Competence Translate into Financial Performance? An Empirical Analysis of Supplier-Customer Relationships. Decision Sciences, 46, 101-134. https://doi.org/10.1111/deci.12117

Lang, M. H., Lins, K. V., \& Miller, D. P. (2003). ADRs, Analysts, and Accuracy: Does Cross Listing in the United States Improve a Firm's Information Environment and Increase Market Value? Journal of Accounting Research, 41, 347-362. https://doi.org/10.1111/1475-679X.00106

Li, B. (2015). Parent-Subsidiary Companies Distance, Internal Control Quality and Corporate Value. Economy and Management, No. 4, 106-116.

Li, D. X., Li, X., \& Zhang, B. (2011). China's Analysts Earning Forecast Errors and Home Advantage. Finance \& Economics, No. 3, 26-33.

Li, X. L., \& Ren, Y. (2013). Securities Analysts' Watch and Audit Supervision: Substitution or Complementary Effect: Empirical Evidence from Chinese Private Listed Companies. Audit \& Economy Research, No. 6, 20-28.

Liu, W. J. (2014). Does the Auditor's Geographic Location Affect Audit Quality? Auditing Research, No. 1, 81-89. 
Malloy, C. J. (2005). The Geography of Equity Analysis. The Journal of Finance, 60, 719-755. https://doi.org/10.1111/j.1540-6261.2005.00744.x

Pei, H. M., \& Du, X. Q. (2015). The Geographic Proximity Between Auditors and Clients, Monitoring Intensity, and Audit Quality. Contemporary Accounting Review, No. 2, $1-23$.

Shen, H. H., Wang, H., \& Wu, L. S. (2017). The Collusion Effect of Local Auditors. Accounting Research, No. 2, pp.

Stein, J. C. (2002). Information Production and Capital Allocation: Decentralized versus Hierarchical Firms. The Journal of Finance, 57, 1891-1921. https://doi.org/10.1111/0022-1082.00483

Wan, Q., Cheng, X. K., Yang, M. J., \& Ouyang, C. Y. (2019). Can the Geographical Proximity of Large Customers Inhibit Corporate Fraud? China Soft Science, No. 8, 100-119.

Wang, J. X., Wang Y. T., \& Lu, G. H. (2016). Can Geographical Distance Affect the Behaviors of Financial Analysts? Journal of Central University of Finance \& Economics, 1, 61-72.

Zhang, H. H., Ping, F., \& Zhang, L. Y. (2019). Independent Director's Geographical Distance and Financial Reporting Quality_Evidence from China. Auditing Research, 207, 83-92.

Zhou, D. H., \& Zhao, Y. J. (2015). Can Analyst Follow-Up Reduce Audit Costs? Empirical Evidence from China's Securities Market. Securities Market Herald, No. 1, 13-18. 